\title{
Recurrence Rate of Giant Cell Tumor With the Treatment of Scooping Curettage, Burr Down Technique, Phenolization, and Bone Cement
}

Syed Faraz Ul Hassan Shah Gillani ${ }^{1}$, Yasir Iqbal ${ }^{2}$, Muhammad Taqi ${ }^{1}$, Tauseef Ahmad Blouch ${ }^{3}$, Muhammad Iqbal ${ }^{4}$, Abubakar Siddiq ${ }^{5}$

1. Orthopedic Surgery, King Edward Medical University/Mayo Hospital, Lahore, PAK 2. Orthopedics, Swat Medical Complex and Teaching Hospital, Swat, PAK 3. Orthopedics and Traumatology, Mayo Hospital, Lahore, PAK 4. Orthopedics and Traumatology, Swat Medical Complex and Teaching Hospital, Swat, PAK 5. Orthopedics and Traumatology, Lahore General Hospital, Lahore, PAK

Corresponding author: Muhammad Taqi,dr.taqi227@gmail.com

\section{Abstract}

Objective: To find the recurrence and outcomes of giant cell tumors treated with scooping curettage, burr down technique, phenolization, and bone cement.

Method: We conducted a descriptive case series using a non-probability consecutive sampling technique at the Department of Orthopedics, Lahore General Hospital, Lahore, Pakistan, from May 2014 to June 2018. A total of 40 patients aged between 20 to 40 years with Compannacci grade I, II \& III giant cell tumors (GCT) were included and patients unfit for the surgery, those with multiple, recurrent, malignant giant cell tumors, tumors involving the axial skeleton, and previously treated cases were excluded. We recorded the side, site of the tumor, post-operative distal neurovascular status, and recurrence of giant cell tumors. The patients were follow-up in the out-patient department (OPD) at the second week, fourth week, 12th week, 24th week, 48th week, 96th week, and 144th week after the surgery. Side, site of the tumor, and post-operative distal neurovascular status were assessed clinically, and recurrence of the tumors was observed clinically and radiologically.

Results: The mean age of all patients was $25.75 \pm 5.74$ years. Males were $45 \%$ (18) and females were $55 \%$ (22). Most $(12,30 \%)$ tumors were present in the upper limb, and 22 (70\%) were present in the lower limb. The majority $(24,60 \%)$ tumors were present around the knee joint. Companacci grade I was five (12.5\%), grade II was 14 (35\%), and grade III was 21 (52\%). There were six (15\%) pathological fractures. There was no case of distal neurovascular (DNV) injury, and three patients had a recurrence in two years of follow-up.

Conclusion: Giant cell tumor treated with scooping curettage, burr down technique, phenolization and polymethyl methacrylate showed $7.5 \%$ recurrence. The combined use of local adjuvants in the treatment of giant cell tumors is a safe and effective way to reduce the rate of local recurrence.

Review began 11/04/2020 Review ended 12/06/2020 Published 12/07/2020

\section{() Copyright 2020}

Gillani et al. This is an open access article distributed under the terms of the Creative Commons Attribution License CC-BY 4.0., which permits unrestricted use, distribution, and reproduction in any medium, provided the original author and source are credited.
Categories: Pathology, Oncology, Orthopedics

Keywords: scooping curettage, burr down, phenolization, bone cementing, giant cell curettage, gct recurrence, gct treatment

\section{Introduction}

Giant cell tumor (GCT) is a locally aggressive benign tumor of the bone. It affects the young adult population with a peak incidence occurring in the third decade of life and 70\% of tumors reported between 20 and 40 years. It causes joint deformity due to bone destruction and may result in disability [1]. It represents approximately $20 \%$ of all benign bone tumors [2,3]. Females have a high incidence of GCTs. Approximately $60 \%$ of GCTs are localized around the knee joint. Due to their divergent biological behavior, they are generally locally aggressive, but few can metastasize to the lung or may transform into osteosarcoma or osteofibroma $[4,5]$.

It has characteristic multinucleated giant cells with mononuclear stromal cells. Anatomically, they are located in the diaphyseal region of the bone and present as pain, swelling, joint effusion in the affected area, and disability [6]. Surgical treatment is used for most GCT tumors [7]. Literature has reported different treatment options; including curettage that has different options such as bone grafting, cement, and bone substitution. Phenolization with various options such as bone grafting and cement. Other options include cryosurgery, radiation therapy, and embolization of the feeding vessel [8].

Data also reported intralesional curettage with high-speed burring of the cavity. This technique has been associated with a low re-occurrence rate of $12 \%$ to $25 \%$. The addition of bone cement and phenol packing with curettage provides thermal effects and thorough removal of soft tissue $[9,10]$. The re-occurrence rate is 


\section{Cureus}

$10 \%$ to $20 \%$ with high-speed burr and adjuvant therapy and $50 \%$ to $60 \%$ with conventional curettage technique [10].

The re-occurrence of GCT is a problem for treating surgeons and patients. The superiority of one treatment over the other is not clear in the literature and our population. This study aimed to determine the rate of reoccurrence of GCT tumors with scooping curettage, burr down technique, phenolization, and bone cement.

\section{Materials And Methods}

This was a descriptive case study performed using a non-probability consecutive sampling technique in the Department of Orthopedic Surgery, Lahore General Hospital, Lahore, from May 2014 to June 2018. We included 40 patients aged between 20 and 40 years of either sex with giant cell tumor of the bone diagnosed on history, clinical examination, radiography, magnetic resonance imaging, and later confirmed on biopsy. Demographic evaluation is shown in Table 1 . We excluded patients unfit for surgery, recurrent, malignant giant cell tumor, or tumor involving the axial skeleton.

\begin{tabular}{|c|c|c|}
\hline variables & Frequency $(\mathrm{N}=\mathbf{2 0})$ & Percent (\%) \\
\hline & 18 & $45 \%$ \\
\hline Females & & \\
\hline Mean ages of the patients in years & $25.75 \pm 5.74$ years & \\
\hline Limb involved Upper limb & 12 & $30 \%$ \\
\hline Lower limb & 22 & $70 \%$ \\
\hline Site and side of the Tumor Right Proximal Tibia & 06 & $15 \%$ \\
\hline Right Distal Femur & 04 & $10 \%$ \\
\hline Left Distal Femur & 06 & $15 \%$ \\
\hline Right Distal Tibia & 04 & $10 \%$ \\
\hline Left Proximal Tibia & 08 & $20 \%$ \\
\hline Right Distal Radius & 08 & $20 \%$ \\
\hline Left Distal Radius & 04 & $10 \%$ \\
\hline Compannaci grading Garde I & 05 & $12.5 \%$ \\
\hline Grade II & 14 & $35.0 \%$ \\
\hline Grade III & 21 & $52.5 \%$ \\
\hline Pathological Fracture Yes & 06 & $15 \%$ \\
\hline No & 34 & $85 \%$ \\
\hline Tumor extension T1 & 25 & $62.5 \%$ \\
\hline T2 & 15 & $37.5 \%$ \\
\hline Distal neurovascular injury Yes & 00 & $00 \%$ \\
\hline No & 40 & $100 \%$ \\
\hline Re-occurrence of tumor Yes & 03 & $7.5 \%$ \\
\hline$\Lambda$ & 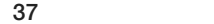 & $2.5^{\circ}$ \\
\hline
\end{tabular}

TABLE 1: Demographic data of the patients

We obtained ethical approval from the institutional review board (126-13/065). Informed written consent was taken. We recorded patients' demographic data. All patients underwent scooping curettage, burr down, phenolization, and bone cement (polymethyl methacrylate [PMMA]). Patients were under general or spinal 


\section{Cureus}

anesthesia during the operation and all had received prophylactic intravenous antibiotics prior to and for 24 hours after the procedure. A prior biopsy was obtained through a longitudinal incision to confirm the tumor type. All procedures were performed by a single surgical team to control bias in the study. The patients were moved to the ward. Follow-up was done for two years by the researcher. Patients were followed and there was no loss to follow-up present. Radiological and clinical evaluations were performed during the follow-up period to note the recurrence rate, and all the information was recorded on a specially designed proforma. Recurrence was measured as the occurrence of giant cell tumors within 24 months after surgery with scooping curettage, burr down, phenolization, and PMMA.

We evaluated the distal neurovascular status of all patients after complete recovery from anesthesia. We removed the suction drain 24 hours after surgery and the surgical wound dressing was done. Range of motion exercises was encouraged on the first postoperative day. Weight-bearing, in the case of the lower limb, was encouraged on the first postoperative day. Tumor site, size, and recurrence were reviewed. Assessment of recurrence with specific signs - swelling, pain, pathological fracture, radiographic serial changes. A biopsy was taken for confirmation of recurrence of GCT or possible malignant transformation. All patients were followed up on the first, seventh, and 15th postoperative days and then monthly for the first year and every three months during the second year, and data were collected as per Table 2 .

\begin{tabular}{|c|c|c|c|}
\hline & & Frequency & Percent \\
\hline \multirow{7}{*}{ Tumor site } & Left distal femur & 2 & $10 \%$ \\
\hline & Right distal femur & 3 & $15 \%$ \\
\hline & Left distal radius & 2 & $10 \%$ \\
\hline & Left proximal tibia & 4 & $20 \%$ \\
\hline & Right distal radius & 4 & $20 \%$ \\
\hline & Right distal tibia & 2 & $10 \%$ \\
\hline & Right proximal tibia & 3 & $15 \%$ \\
\hline Total & & 20 & $100 \%$ \\
\hline
\end{tabular}

TABLE 2: Distribution of tumor site of patients

Statistical Package for Social Sciences (SPSS) version 20.0 (IBM Corp., Armonk, NY, USA) was used to analyze the collected data. Quantitative variables such as age were presented as mean and standard deviation. Qualitative variables such as sex, site of the tumor, wound examination, and recurrence were presented as frequency and percentages.

\section{Results}

The mean age of all patients was $25.75 \pm 5.74$ years. The mean ages of male and female patients were $26 \pm 5.54$ and $25.44 \pm 6.30$ years, respectively. The age of male patients was higher than that of female patients. Gender distribution showed that $45 \%$ of the patients were female while $55 \%$ of the patients were male. The tumor site of the patients is given in Table 2. Two patients had a GCT tumor on the left distal femur, three patients had a tumor on the right distal femur, two patients had a tumor on the left distal radius, four patients had a tumor on the left proximal tibia, four patients had a tumor on the right distal radius, two patients had a tumor on the right distal tibia, and three patients had a tumor on the right proximal tibia. Patients' followup was performed from first postoperative day until 24 months. There was not a single case report of distal neurovascular injury or cortical breach during the course of follow-up, none of the patients had any kind of abnormality in the wound. All patients' wounds were normal at the last follow-up. Only three patients had a recurrence of the tumor after surgery until the last follow-up. One recurrence appeared in the distal femur, and two were present in the proximal tibia.

\section{Discussion}

The treatment of GCT is challenging for orthopedic surgeons due to its divergent biological behavior. The aim of GCT treatment is associated with the expectation of good functional outcomes and to avoid the risk of tumor reoccurrence. Simple curettage has a better functional outcome, however, it is associated with a high incidence of reoccurrence, while the addition of adjuvant treatment has reduced the reoccurrence rate [11]. Treatment with high-speed burr and cementation offers a low reoccurrence rate, early stabilization, and early radiological diagnosis of reoccurrence [12]. 
The high reoccurrence rate has caused surgeons to enhance their surgical technique with the addition of adjuvants including liquid nitrogen [13], acrylic cement [14], phenol [15], hydrogen peroxide [16], and locally administered chemotherapy. Previously, radiation therapy was associated with malignant transformation, but this concept has been challenged because of the availability of modern radiotherapy treatment [17].

The agreement on the treatment of locally recurrent tumors is controversial. The literature reported different treatment options for second or third curettage based on the pathology and aggressiveness [18]. Bone cement has been accepted as an adjuvant in the treatment of GCT with curettage and bone grafting.

When curettage is compared with bone grafting (autograft or allograft) as filling materials with bone cement, it is less expensive, provides early stability, minimal risk of joint degeneration, and early detection of GCT reoccurrence $[8,10]$. A study conducted in Singapore reported no reoccurrence in cases of GCT tumors treated with curettage, high-speed burring, bone cement, or adjuvant treatment. They reported a $44 \%$ reoccurrence among patients in whom adjuvant treatment was not advocated [19]. However, one study reported a $20-56 \%$ reoccurrence rate among patients who received adjuvant therapy, liquid therapy, and phenol. They reported reoccurrence in the first 30 months after the first treatment [20].

A multicenter study conducted by Turcotte et al. on 186 patients, found no significant difference in the recurrence rates when high-speed burr was compared with other local adjuvants [21].

An Iranian study in their case series of 168 patients reported $18.2 \%$ and $37.5 \%$ recurrence with curettage, high-speed burring, and curettage, respectively. According to this study, high-speed burring is an effective method for reducing recurrence [22].

Pritsch et al. treated 60 cases of GCT with extended curettage and cryosurgery. He reported a $17 \%$ fracture in his cases [23]. They never reported internal fixation in fracture cases. We performed internal fixation in our study on weight-bearing bone presenting with a fracture. All but one of our cases with the involvement of long bones in the lower extremity received plate or screw augmentation. As a result, reconstruction failed in only one patient with extensive proximal tibial involvement.

We observed 7.5\% recurrence in our study among patients treated with scooping curettage, high-speed burring, phenolization, and bone cement. Our results are similar to those reported in the literature.

Our study had some limitations: small sample size, single-center, and short follow-up. Future studies may extend the findings of our study.

\section{Conclusions}

Giant cell tumor treated with curettage, high-speed burring with the addition of adjuvant treatment with phenol and bone cement was a useful and safe method of treatment with zero recurrences, immediate stabilization, and early weight-bearing. It was also proved that the combined use of local adjuvants in the treatment of giant cell tumors is a safe and effective way to reduce the rate of local recurrence.

\section{Additional Information \\ Disclosures}

Human subjects: Consent was obtained by all participants in this study. Advanced Studies \& Research Board issued approval uhs/Education/126-13/065. This study is relevant because GCT is a benign aggressive tumor with malignant potential. There are different options for GCT but we there must be the categorization of treatment option on the basis of outcome. All study parameters are approachable, measurable, and up to the mark in terms of ethical guidelines. Animal subjects: All authors have confirmed that this study did not involve animal subjects or tissue. Conflicts of interest: In compliance with the ICMJE uniform disclosure form, all authors declare the following: Payment/services info: All authors have declared that no financial support was received from any organization for the submitted work. Financial relationships: All authors have declared that they have no financial relationships at present or within the previous three years with any organizations that might have an interest in the submitted work. Other relationships: All authors have declared that there are no other relationships or activities that could appear to have influenced the submitted work.

\section{References}

1. Giant Cell Tumor Of Bone. (2010). https://orthoinfo.aaos.org/en/diseases--conditions/giant-cell-tumor-ofbone/.

2. Alberghini M, Giunti A, Baldini N: Histogenetic characterization of giant cell tumor of bone. Clin Orthop Relat Res. 2008, 466:2081-91. 10.1007/s11999-008-0327-z

3. Algawahmed H, Turcotte R, Farrokhyar F, Ghert M: High-speed burring with and without the use of surgical adjuvants in the intralesional management of giant cell tumor of bone: a systematic review and metaanalysis. Sarcoma. 2010, 2010:586090. 10.1155/2010/586090 
4. Altmann AE, Halliday JL, Giles GG: Associations between congenital malformations and childhood cancer. A register-based case-control study. Br J Cancer. 1998, 78:1244-9. 10.1038/bjc.1998.662

5. Angtuaco EJ, Fassas AB, Walker R, Sethi R, Barlogie B: Multiple myeloma: clinical review and diagnostic imaging. Radiology. 2004, 231:11-23. 10.1148/radiol.2311020452

6. Antoch G, Vogt FM, Freudenberg LS, et al.: Whole-body dual-modality PET/CT and whole-body MRI for tumor staging in oncology. JAMA. 2003, 290:3199-206. 10.1001/jama.290.24.3199

7. Aoki J, Watanabe H, Shinozaki T, et al.: FDG PET of primary benign and malignant bone tumors: standardized uptake value in 52 lesions. Radiology. 2001, 219:774-7. 10.1148/radiology.219.3.r01ma08774

8. Arbeitsgemeinschaft K, Becker W, Dohle J, et al.: Local recurrence of giant cell tumor of bone after intralesional treatment with and without adjuvant therapy. J Bone Joint Surg Am. 2008, 90:1060-7. 10.2106/JBJS.D.02771

9. Ardran, GM: Bone destruction not demonstrable by radiography . Br J Radiol. 1951, 24:107-9. 10.1259/00071285-24-278-107

10. Atkins GJ, Haynes DR, Graves SE, Evdokiou A, Hay S, Bouralexis S, Findlay DM: Expression of osteoclast differentiation signals by stromal elements of giant cell tumors. J Bone Miner Res. 2000, 15:640-9.

11. Balke M, Schremper L, Gebert CH, et al.: Giant cell tumor of bone: treatment and outcome of 214 cases . J Cancer Res Clin Oncol. 2008, 134:969-78. 10.1007/s00432-008-0370-x

12. Bini SA, Gill K, Johnston JO: Giant cell tumor of bone. Clin Orthop Relat Res. 1995, 321:245-50.

13. Faur CL: Liquid nitrogen efficiency in treatment of giant cell tumor of bone and prevention of recurrence . Appl Sci. 2020, 10:6310. 10.3390/app10186310

14. Saikia KC, Bhattacharyya TC, Bhuyan SK, Bordoloi B, Durgia B, Ahmed F: Local recurrences after curettage and cementing in long bone giant cell tumor. Indian J Orthop. 2011, 45:168-173.

15. Hasan O, Ali M: Treatment and recurrence of giant cell tumors of bone - a retrospective cohort from a developing country. Ann Med Surg (Lond). 2019, 48:29-34. 10.1016/j.amsu.2019.10.010

16. Omlor GW: Retrospective analysis of 51 intralesionally treated cases with progressed giant cell tumor of the bone: local adjuvant use of hydrogen peroxide reduces the risk for tumor recurrence. World J Surg Onc. 2019, 69:73. 10.1186/s12957-019-1613-9

17. Feigenberg SJ, Marcus RB Jr, Zlotecki RA, Scarborough MT, Berrey B, Hudson, Enneking WF: Radiation therapy for giant cell tumors of bone. Clin Orthop Relat Res. 2003, 411:207-216. 10.1097/01.blo.0000069890.31220.b4

18. Mavrogenis AF: Giant cell tumor of bone revisited. SICOT J. 2017, 3:54. 10.1051/sicotj/2017041

19. Lim YW, Tan MH: Treatment of benign giant cell tumours of bone in Singapore . Ann Acad Med Singap. 2005, 34:235-7.

20. López-Pousa A, Broto JM, Garrido, Vázquez J: Giant cell tumour of bone: new treatments in development . Clin Transl Oncol. 2015, 17:419-430. 10.1007/s12094-014-1268-5

21. Turcotte RE, Wunder JS: Giant cell tumor of long bone: a Canadian Sarcoma Group study . Clin Orthop Relat Res. 2002, 397:248-258. 10.1097/00003086-200204000-00029

22. Jamshidi K, Sami SH: Local recurrence in giant cell tumor of bone: comparative study of two methods of surgical approach. JRMS. 2008, 13:223-229.

23. Pritsch T, Bickels J, Wu C-C, Squires HM, Malawer MM: The risk for fractures after curettage and cryosurgery around the knee. Clin Orthop Relat Res. 2007, 458:159-167. 10.1097/BLO.0b013e318038fc3d 